profession of the value of a single anticonvulsant assay and the consequent overinterpretation of the plasma concentration obtained. Too often the "Everest" factor takes over: measure it because it's there. Many doctors believe that the "therapeutic range" is writ large in tablets of stone, and herein lies the root of the problem.

The term "therapeutic," as applied to a range of drug concentrations, begs the question of efficacy, refers to populations rather than individual patients, and should be discarded. Even with phenytoin, the drug for which there is most evidence to support a concentration-effect-toxicity relation, a substantial minority of epileptic patients remain free of fits, with concentrations below the quoted range, ${ }^{24}$ while in others complete control of seizures may be obtained only with serum phenytoin concentrations greatly exceeding the recommended upper limit. ${ }^{5}$ Moreover, the diagnosis of central nervous system toxicity is also made on clinical grounds. The doctor must ask the patient, not the biochemist, whether an anticonvulsant concentration is therapeutic or toxic.

Measurement of circulating anticonvulsant concentrations may be useful when a specific clinical question needs to be answered, particularly in assessing compliance or estimating the likely leeway for an increase in dose. ${ }^{6}$ Ideally, this information should be available immediately. In an ongoing prospective evaluation of anticonvulsant monitoring at the epilepsy clinic at this hospital one third of nearly 700 assays performed over a year showed a plasma concentration that surprised the requesting doctor. The numbers of unexpectedly low and unexpectedly high concentrations were similar. In more than $20 \%$ of these patients an alteration in intended action resulted. This ability to measure anticonvulsant concentrations at the clinic is enormously helpful, particularly for younger doctors with limited experience in the management of epilepsy.

It is our policy to regard the quoted range as a target, around which some sort of clinical improvement might be expected without the production of toxicity. ${ }^{6} \mathrm{~A}$ further adjustment in anticonvulsant dose may then be made according to the clinical response or the development of central nervous side effects. The target range retains the important elements of therapeutic drug monitoring without assuming a "therapeutic" validity that it does not possess.

Department of Medicine,

MARTIN J BRODIE

Gardiner Institute

Western Infirmary,
Glasgow G11 6NT

1 Brodie MJ, McIntosh ME, Hallworth M. Therapeutic drug monitoring - the need for audit? Scou Med f 1985;30:75-82.

2 Feldman RG, Pippenger CE. The relation of anticonvulsant drugs to complete seizure control. f Clin Pharmacol 1976;16: 51-9.

3 Shorvon SD, Chadwick D, Galbraith AW, Reynolds EH. One drug for epilepsy. BrMed J 1978;i:474-6.

4 Callaghan N, Kenny RA, O'Neill B, Crowley M, Goggin T. A prospective study between carbamazepine, phenytoin and sodium valproate as monotherapy in previously untreated and recently diagnosed patients with epilepsy. $f$ Neurol Neurosurg Psychiatry 1985;48:639-44.

5 Gannaway DJ, Mawer GE. Serum phenytoin concentration and clinical response in patients with epilepsy. Br $\mathcal{C}$ Clin Pharmacol 1981;2:833-9.

6 Brodie MJ. Therapeutic drug monitoring. Practitioner 1986;230: 1003-9.

\section{Effect of dietary cholesterol on plasma cholesterol concentration}

SIR,-Professor P J Nestel (4 April, p 901) comments on our paper, which suggested that modest changes in cholesterol intake have little effect on plasma cholesterol concentrations in people who have reduced their intake of saturated fat and increased that of fibre rich carbohydrate
(7 February, p 333). He points out that a reduction headaches for the team. It is encouraging to see in cholesterol of around $0.1 \mathrm{mmol} / \mathrm{l}$ could, on the that other health authorities are starting to provide basis of epidemiological evidence, be associated for the travellers. The development of liaison with a substantial benefit in terms of reduction of between these different areas will, I hope, allow the coronary heart disease. From prospective observa- provision of better services for the travelling tions on those screened in the multiple risk factor population.

intervention trial, the most recent and largest set of longitudinal data, such change $(2 \%)$ might be expected to produce a $2 \cdot 3 \%$ reduction in

mortality from coronary heart disease over six years. Professor Nestel's comments illustrate the difficulty in interpreting negative findings.

The observed difference between those eating two and seven eggs a week was $0 \cdot 13$ ( $95 \%$ confidence interval 0.03 to 0.23 ) after four weeks and 0.12 ( 0 to 0.23 ) after eight weeks. This study included far more participants than most other investigations of the relation between dietary cholesterol and cholesterol in the blood. It is difficult, at least for us, to contemplate the much larger study that would be necessary to be more certain about the absence of an effect or to show with greater certainty a small effect.

Weagree that our findings cannot be extrapolated to subjects who have not appreciably reduced their intake of saturated fat or to more extreme contrasts of dietary cholesterol intakes, under which conditions most previous studies have been carried out. Many dietary recommendations for reducing blood cholesterol give considerable prominence to the role of dietary cholesterol. We wished to emphasise the central role of restricting saturated fat intake, that modest changes in dietary cholesterol in those who have already restricted their saturated fat intake seem to have no, or little, effect, and that in the circumstances of our experimental design there is no evidence of a population of hyper-responders to dietary cholesterol. Permitting a little flexibility in intake of dietary cholesterol may help to enhance compliance with other and more important recommendations.

J I MANN

JACQUELINE EDINGTON

Department of Community Medicine and General Practice, Radcliffe Infirmary, Oxford OX2 6HE

\section{Health care for travellers}

SIR,-I am very pleased to see that the health of travellers is now being taken seriously (Dr Allison Streetley, 21 February, p 492). ${ }^{1}$ West Glamorgan Health Authority has been taking an interest in travellers' families for some time.

For over three years a team composed of one health visitor and one clinical medical officer (child health) has offered health facilities to the travellers' families, concentrating on the needs of children and mothers. We thought that having one designated health visitor, who made regular visits, would increase the take up of services by mothers. The services provided on the site are counselling, check ups for children, immunisations, and referrals to other services (chiropody, audiology); recently a family planning and cytology programme has been planned.

Our main problems are caused by the terrible conditions of the sites, which are illegal and have none of the usual facilities of legal sites. The county council has so far been unable to open a site under the Caravan Sites Act 1968 because of the hostility of the local population. Another difficulty has been access to general practitioners' surgeries because few local general practitioners will agree to take travellers on their lists, and even fewer will visit them.

Lack of medical records and unsatisfactory liaison with other agencies are another source of
SIR,-I should like to congratulate $\mathrm{Mr}$ James Owen Drife on his comments on consultant (28 March, p 789). Though several other useful reminders on the subject have been published recently there is a danger that the medical hierarchy will close ranks on the problem of accountability in the hope that it will disappear. It will not. We live in a highly competitive world that is actively pursuing systems of accountability in all its spheres-governmental, financial, industrial, educational, etc-and medicine is not exempt. We must never forget that we exist first and foremost to provide a service for our patients.

The reluctance in medical circles to criticise is deep rooted and continues to be taught by example, or rather by the lack of it. Reluctance to accept criticism is even more entrenched and more sinister. Too often "clinical freedom" is upheld as the underlying phenomenon behind this reluctance, but we all know of cases where this is totally inappropriate. No one will deny the importance of clinical freedom for the practitioner, but this does not encompass abuse of the system, patients, or colleagues.

Let us step down from our imaginary pedestals and admit that we are human and fallible. Consultants, by virtue of their position at the top of the ladder, must take the lead, and, out of necessity, the rest of us will follow.

GAIL C GRICE

Flitton,

Bedfordshire MK45 5DY

SIR,-Consultants are already accountable to their licensing authority, the General Medical Council, as well as to every other law of the country in common with other citizens.

As the wife of a doctor who has been the victim of the HM (61)112 procedure and the 190 procedure for almost five years, may I suggest that the major reason for long delays, injustice to doctors, distress to their families, and great expense to the National Health Service and the defence societies is the incorrect use of disciplinary procedures. In my husband's case, and others I know of, I believe that disciplinary procedures are being used for management disputes of a political nature ${ }^{12}$ and disagreements within specialties. ${ }^{3}$

Mr James Owen Drife (28 March, p 789) mentions the possibility of regular appraisal of consultants' work being linked to the distinction award system, but the weakness of this system stems from the fact that the criteria by which some consultants are judged worthy of extra pay is secret and, therefore, others cannot emulate them. It is not unknown for consultants who are recipients of distinction awards to fall foul of the HM (61)112 procedure.

Mr James Owen Drife has not one word of sympathy for an innocent doctor debarred from his or her vocation and isolated from colleagues, patients, and public by the ignominy of suspen-

\section{Consultant accountability} accountability, a difficult and controversial issue 